\title{
Protective effect of vaginal application of neutralizing and nonneutralizing inhibitory antibodies against vaginal SHIV challenge in macaques
}

\author{
C Moog ${ }^{1}$, N Dereuddre-Bosquet ${ }^{2,3}$, J-L Teillaud ${ }^{4}$, ME Biedma ${ }^{1}$, V Holl ${ }^{1,11}$, G Van Ham ${ }^{5}$, L Heyndrickx ${ }^{5}$, \\ A Van Dorsselaer ${ }^{6}$, D Katinger ${ }^{7}$, B Vcelar ${ }^{7}$, S Zolla-Pazner ${ }^{8}$, I Mangeot ${ }^{2,3}$, C Kelly ${ }^{9}$, RJ Shattock ${ }^{10}$ \\ and $\mathrm{R}$ Le Grand ${ }^{2,3}$
}

Definition of antibody (Ab) functions capable of preventing mucosal HIV transmission may be critical to both effective vaccine development and the prophylactic use of monoclonal Abs. Although direct antibody-mediated neutralization is highly effective against cell-free virus, increasing evidence suggests an important role for immunoglobulin $G$ (IgG) Fc $\gamma$ receptor (FcyR)-mediated inhibition of HIV replication. Thus, a panel of well-known neutralizing (NAbs) and nonneutralizing Abs (NoNAbs) were screened for their ability to block HIV acquisition and replication in vitro in either an independent or Fc $\gamma \mathrm{R}$-dependent manner. Abs displaying the highest Fc-mediated inhibitory activity in various in vitro assays were selected, formulated for topical vaginal application in a microbicide gel, and tested for their antiviral activity against SHIVSF162P3 vaginal challenge in non-human primates (NHPs). A combination of three NAbs, 2G12, $2 \mathrm{~F} 5$, and 4E10, fully prevented simian/human immunodeficiency virus (SHIV) vaginal transmission in 10 out of 15 treated NHPs, whereas a combination of two NoNAbs, 246-D and 4B3, although having no impact on SHIV acquisition, reduced plasma viral load. These results indicate that anti-HIV Abs with distinct neutralization and inhibitory functions differentially affect in vivo HIV acquisition and replication, by interfering with early viral replication and dissemination. Therefore, combining diverse Ab properties may potentiate the protective effects of anti-HIV-Ab-based strategies.

\section{INTRODUCTION}

Neutralizing antibodies (NAbs) have long been considered central to effective mucosal protection against HIV acquisition. Intravenous infusion of NAbs ${ }^{1}$ can fully protect non-human primates (NHPs) from experimental mucosal simian/human immunodeficiency virus (SHIV) challenge. ${ }^{2-5}$ However, other $\mathrm{Ab}$ properties might also play a role in antibody-mediated protection in addition to neutralization of infectious viral particles. ${ }^{6,7}$ It is now widely accepted that nonneutralizing antibodies (NoNAbs) as well as NAbs display inhibitory activities against HIV-1 replication in vitro based on different mechanisms. ${ }^{8}$ In the RV144 Thai phase III trial, ${ }^{9}$ a reduced risk of infection (31\%) in vaccinated individuals did not correlate with serum neutralizing activities but with high concentrations of anti-V1-V2 NoNAbs, ${ }^{10}$ providing additional support for a possible contribution of NoNAb functions to protection. ${ }^{9}$

Neutralization is thought to require antibody $(\mathrm{Ab})$ binding to the functional trimeric envelope spike, preventing receptor engagement (CD4 and coreceptor) and/or conformational change required for HIV fusion and entry. However, HIV

\footnotetext{
${ }^{1}$ U1110 INSERM/UNISTRA, Institute of Virology, Strasbourg, France. ${ }^{2}$ CEA, Division of Immuno-Virology, iMETI, DSV, Fontenay-aux-Roses, France. ${ }^{3}$ UMR-E1, Université Paris Sud-11, Orsay, France. ${ }^{4}$ INSERM UMR-S 872, Cordeliers Research Center, Paris Descartes University, Pierre et Marie Curie University, Paris, France. ${ }^{5}$ Institute of Tropical Medicine and University of Antwerp, Antwerp, Belgium. ${ }^{6}$ UMR 7178 (CNRSUdS), ECPM, Strasbourg, France. ${ }^{7}$ Polymun Scientific GmbH, Klosterneuburg, Austria. ${ }^{8} \mathrm{NYU}$ School of Medicine and New York Veterans Affairs Medical Center, New York, New York, USA. ${ }^{9}$ Clinical and Diagnostic Sciences, King's College, London, UK. ${ }^{10}$ Department of Medicine, Imperial College, London, UK. ${ }^{11}$ Present address: Lab Science Department, Hematology and Flow Department, Covance CLS SA, Geneva, Switzerland. Correspondence: C Moog (c.moog@unistra.fr)
} 
displays a diversity of envelope structures on its membrane in addition to functional trimers that include noncleaved trimers, dimers, monomers, as well as gp41 stumps that have shed gp120. ${ }^{11}$ Abs against these structures are more easily induced but are nonneutralizing. The demonstration that vaginal application of the monoclonal $\mathrm{Ab}(\mathrm{mAb}) \mathrm{b} 12$ (directed against the CD4 binding site of gp120) confers protection in a NHP challenge model provided an important proof of concept for the potential of a NAb-based microbicide. ${ }^{6}$ However, b12 alone leads to insufficient breath of protection against predominant circulating HIV strains to be clinically effective. Furthermore, subsequent passive infusion studies demonstrated that the protective efficacy of this NAb against vaginal SHIV challenge was significantly reduced by the LALA mutation that impaired its binding to Fc $\gamma$ receptors (Fc $\gamma$ Rs). ${ }^{3,12}$ Mechanisms by which the $\mathrm{Fc}$ region of immunoglobulin $\mathrm{G}$ ( $\mathrm{IgG}$ ) participates in this protection are not fully understood. ${ }^{6,8,13,14}$ Antibody-dependent cellular cytotoxicity (ADCC) and antibody-dependent cell-mediated virus replication inhibition require binding to Fc $\gamma$ Rs expressed by killer cells and lead to the killing of HIVinfected cells following their recognition and binding by HIVspecific Abs. ${ }^{8,15}$ Fc-mediated inhibition of HIV replication in antigen-presenting cells (macrophages and dendritic cells) is a mechanism whereby Abs inhibit infection of antigen-presenting cells, most likely through Fc $\gamma \mathrm{R}$-dependent phagocytosis of opsonized viral particles followed by a rapid degradation, as suggested by the blockade of this phenomenon by anti-Fc $\gamma$ Rs Abs. ${ }^{13,16-18}$

In addition to the properties of five well-known NAbs (2G12, 2F5, 4E10, b12, and LALA mutant of b12), we report here an extensive characterization of HIV inhibitory properties of four
NoNAbs selected for their Fc-mediated inhibitory activities. ${ }^{16}$ NAbs 2G12, 2F5, and 4E10 as well as NoNAbs 246-D and 4B3, cumulating high inhibitory scores in diverse in vitro anti-HIV assays, were selected for efficacy testing in NHP vaginal challenge studies. Local application of the combination of NAbs fully prevented SHIV acquisition in 10 out of 15 macaques, whereas the combination of NoNAbs failed to prevent infection. However, this latter combination reduced the peak of plasma viral load, demonstrating that Abs with nonneutralizing capacity are nonetheless able to trigger an Fc-dependent inhibition of HIV replication, leading to in vivo anti-HIV effects that may strengthen those elicited by NAbs.

\section{RESULTS \\ Antibodies significantly inhibit HIV replication in primary cells through Fc-dependent mechanisms}

We previously reported that F240 and 246-D mAbs directed against the principal immune-dominant domain (PID) on gp41 inhibit infection of macrophages expressing Fc $\gamma$ Rs by clade B HIV-1 BaL and BX08 and clade C TV-1 isolates. ${ }^{16}$ We further characterized the inhibitory activities of mAbs on human primary cells in vitro, against the clade B HIV-1 SF162 viral strain. We first showed that the two mAbs F240 and 246-D, as well as the 4B3 anti-PID mAb, but not the 3D6 anti-PID mAb, efficiently inhibit clade B HIV-1SF162 infection of primary human monocyte-derived macrophages (MDMs) with a $90 \%$ inhibitory concentration $\left(\mathrm{IC}_{90}\right)$ in the same order of magnitude $\left(0.1-0.5 \mu \mathrm{g} \mathrm{ml}^{-1}\right)$ as $4 \mathrm{E} 10,2 \mathrm{G} 12$, and b12 NAbs (Figure 1b). The highest activity was observed for $2 \mathrm{~F} 5 \mathrm{mAb}\left(\mathrm{IC}_{90}\right.$ of $\left.0.01 \mu \mathrm{g} \mathrm{ml}^{-1}\right)$. As expected, the b6 mAb, which is a NoNAb recognizing the $\mathrm{CD} 4$ binding site, had a modest activity $\left(\mathrm{IC}_{90}\right.$ of

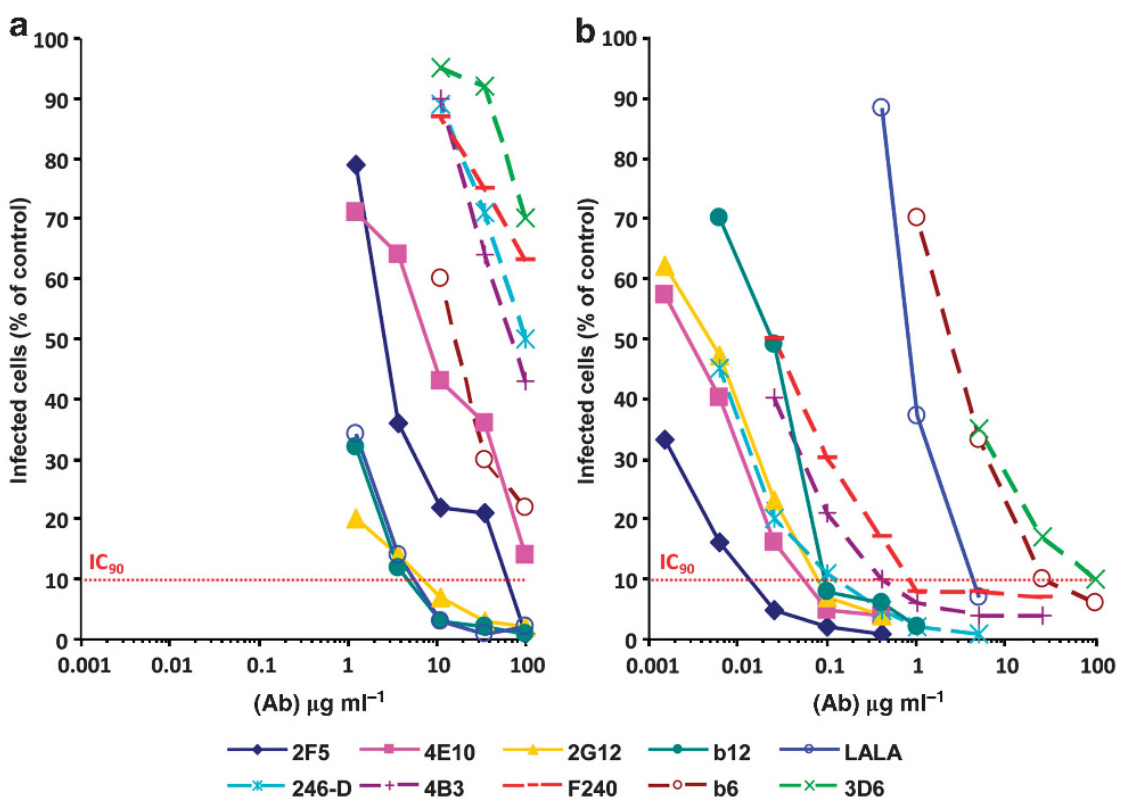

Figure 1 Neutralization and Fc-mediated inhibition. Neutralization and Fc-mediated inhibition of replication by monoclonal antibodies (mAbs) were assessed using HIV-1 SF162 with either (a) peripheral blood mononuclear cells (PBMCs) or (b) monocyte-derived macrophages (MDMs) as HIV target cells. The percentage of infected (a) PBMCs and (b) MDMs infected after $48 \mathrm{~h}$ of culture was measured. Percentages of infected cells in the presence or absence of $\mathrm{mAb}$ were calculated and plotted for different $\mathrm{mAb}$ concentrations. The $\mathrm{IC}_{90}$, i.e., concentration of $\mathrm{mAb}$ able to decrease by $90 \%$ the percentage of infected cells, was defined (dotted red line). 
$30 \mu \mathrm{g} \mathrm{ml}^{-1}$ ) on inhibition of macrophage infection. In addition to Fc-mediated phagocytosis, this assay detects the direct neutralization effect of mAbs. ${ }^{17}$ As a consequence, NAb activity likely results from both neutralizing and Fc-mediated inhibitory activities in this assay. The LALA mutant of b12 mAb that lacks $\mathrm{F} c \gamma \mathrm{R}$ binding capacity ${ }^{19}$ retained its neutralizing activity (Figure 1b) and exhibited similar inhibitory effect $\left(\mathrm{IC}_{90}=\right.$ $6 \mu \mathrm{g} \mathrm{ml}^{-1}$ ) on macrophages and peripheral blood mononuclear cells (PBMCs; Figure 1a). In contrast, anti-PID mAbs did not neutralize infection of PBMCs and only displayed Fc-mediated inhibitory effects on macrophages (Figure 1).

We surmised that anti-PID Ab-mediated inhibition of HIV infection is functionally dependent on Fc $\gamma \mathrm{R}$ binding. As ADCC also involves the binding of $\mathrm{mAb}$ to $\mathrm{Fc} \gamma \mathrm{Rs}$, the capacity of these mAbs to affect infection of $\mathrm{CD}^{+}{ }^{+} \mathrm{T}$ cells through $\mathrm{Fc} \gamma \mathrm{R}$ mediated ADCC was assessed using a new assay involving primary HIV-1 SF162-infected CD4 ${ }^{+} \mathrm{T}$ cells and autologous natural killer (NK) effector cells. Anti-PID 246-D and 4B3 NoNAbs and anti-gp120 b12 and 2G12 NAbs induced the lysis of approximately half of the infected cells $(44 \% \pm 1.4$; $48 \% \pm 4.2 ; 61 \% \pm 7$; and $50 \% \pm 1.4$, respectively) in the presence of NK cells (Figure 2). Under these conditions, the activity of $\mathrm{mAbs}$ was higher than those described in the recently published study by Smalls-Mantey et al. ${ }^{20}$ and could therefore be classified as having significant ADCC activity. The other mAbs tested exhibited poor ADCC. As expected, the b12 LALA mutant had no ADCC activity as compared with the original b12 $\mathrm{mAb}$, confirming the Fc $\gamma$ R dependency of the ADCC assay. Overall, distinct in vitro $\mathrm{Ab}$ inhibitory activities were detected in each of the three functional inhibitory assays. Among the five NAbs, 2F5 displayed the highest $\mathrm{Fc}$-mediated function and low ADCC, whereas b12 exhibited low Fc-mediated inhibition but was the highest for ADCC. The NoNAbs 246-D and 4B3, despite having no neutralizing activity, distinguished themselves by their potent ADCC and Fc-mediated functions.

\section{Binding of anti-HIV mAbs to HIV and Fc $\gamma$ Rs}

$\mathrm{ADCC}$ and $\mathrm{Fc}$-mediated inhibition necessitate both the binding of the Fab region to virus and of the Fc region to Fc $\gamma \mathrm{R}$-bearing cells. Thus, the binding capacity of mAbs to native virus particles and to cells expressing various Fc $\gamma$ Rs was evaluated.

Using a virus capture method, we found efficient binding of HIV-1 SF162 particles to anti-PID 246-D, 4B3, and F240 NoNAbs as well as 2G12 NAb (Figure 3). However, b12, 2F5, and 4 E10 NAbs, as well as the b6 NoNAb poorly captured virions, likely reflecting the poor accessibility of the corresponding epitopes (CD4 binding site and membrane proximal external region) on HIV particles. ${ }^{21}$

We next assessed the binding of mAbs to Fc $\gamma \mathrm{R}$ expressed by primary human MDMs by indirect immunofluorescence. These cells strongly express Fc $\gamma$ RI, and, to a lesser extent, Fc $\gamma$ RII and Fc $\gamma$ RIII. ${ }^{22}$ A strong binding was observed without significant differences between Abs (see Supplementary Figure S1 online). As expected, the binding of b12 to macrophages was Fc mediated, as the LALA mutant was not able to bind these cells. All IgG1 mAbs bound with a similar efficiency to TZM-bl cells expressing high-affinity Fc $\gamma$ RI but exhibited only a weak binding to TZM-bl expressing the other human Fc $\gamma$ Rs, as previously reported. ${ }^{23}$ The binding of mAbs (except F240) to the various human low/intermediate-affinity Fc $\gamma$ Rs was therefore examined using cell lines that strongly express only one of these Fc $\gamma$ Rs (Jurkat-CD16 (Fc $\gamma$ RIIIa ${ }^{+}$), K562 $\left(\mathrm{Fc}_{\mathrm{RIIa}}{ }^{+}\right)$, and IIA1.6IIb2 $\left.\left(\mathrm{Fc} \gamma \mathrm{RIIb}{ }^{+}\right)\right){ }^{24,25}$ Both NAbs (2F5, 2G12, 4E10, and b12) and NoNAbs (246-D, 4B3, and b6) bound to Fc $\gamma \mathrm{RIIIa}^{+}$Jurkat-CD16, Fc $\gamma \mathrm{RIIa}^{+}{ }^{+} \mathrm{K} 562$, and Fc $\gamma$ RIIb2 $^{+}$IIA1.6 IIb2 ${ }^{+}$cells, but to different extents

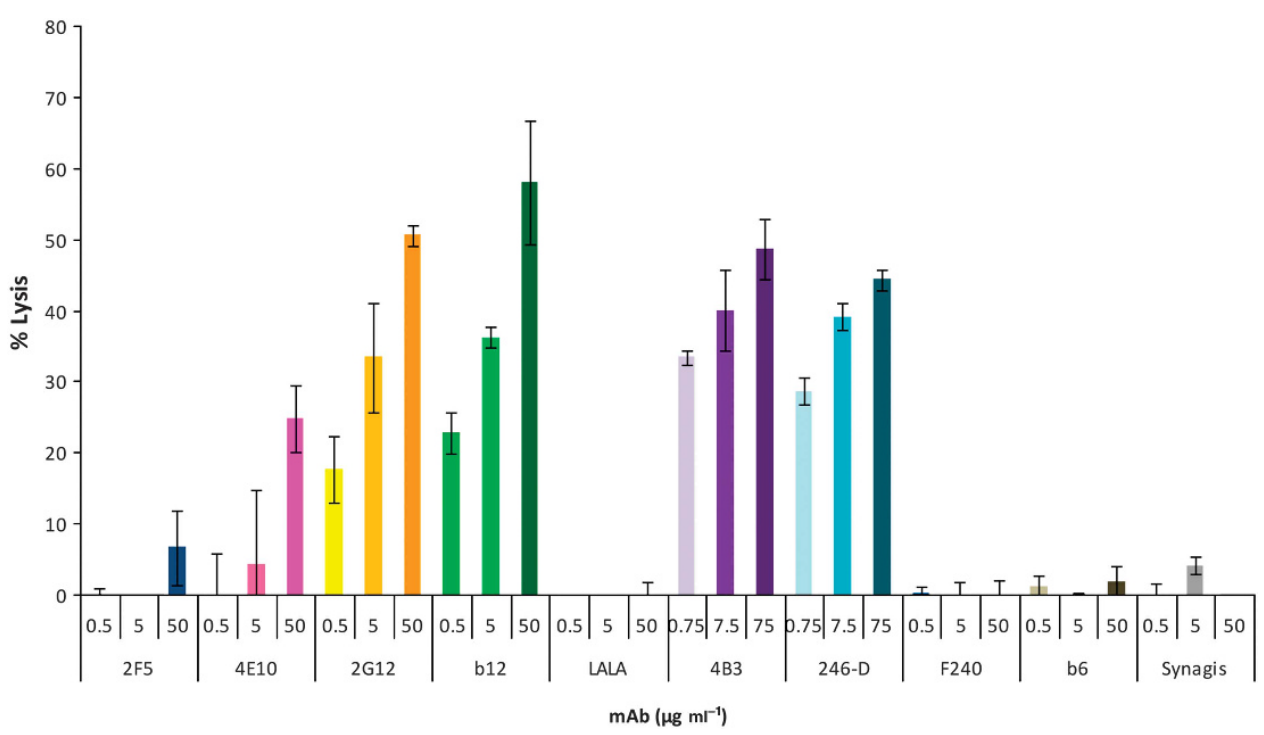

Figure 2 Antibody-dependent cell cytotoxicity (ADCC) on primary target $(T)$ and effector (E) cells. ADCC was assessed on primary infected CD4 ${ }^{+}$. enriched cells using autologous natural killer (NK) cells as effector cells with three dilutions of monoclonal antibodies (mAbs) $(E / T$ ratio $=1: 1)$. The percentage of infected cells was recorded and the percentage of lysis in the presence of mAb compared with NK cells alone (direct lysis) was calculated as: ( $\%$ infected CD4 ${ }^{+} \mathrm{T}$ cells in presence of $\mathrm{NK}-\%$ infected $\mathrm{CD} 4^{+} \mathrm{T}$ cells in presence of $\left.\mathrm{NK}+\mathrm{mAb}\right) \div \%$ infected $\mathrm{CD} 4^{+} \mathrm{T}$ cells in presence of $\left.\mathrm{NK}\right)$ $\times 100$. 


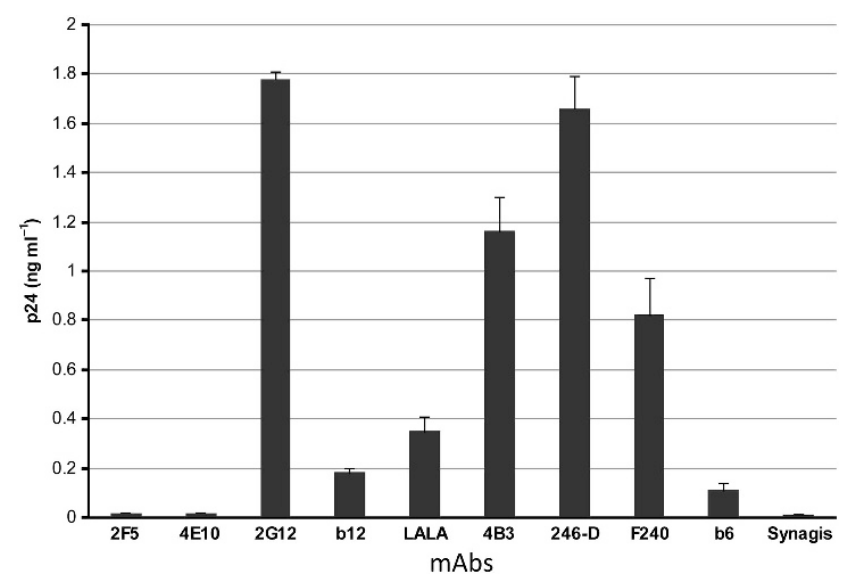

Figure 3 Antibody (Ab) capture of native HIV particles. The capacity of the different monoclonal antibodies (mAbs) to capture native HIV particles was assessed by enzyme-linked immunosorbent assay (ELISA). HIV particles retained by the mAbs were lysed and quantified by p24 detection by ELISA. High p24 concentration was associated with efficient binding of native HIV particles to mAb. Nonspecific mAb (Synagis) was used as negative control.

Table 1 Binding of anti-HIV antibodies to Fc $\gamma \mathrm{RIIIa}^{+}$, Fc $\gamma$ RIla $^{+}$-, and Fc $\gamma$ RIIb2 ${ }^{+}$-expressing cells

\begin{tabular}{|c|c|c|c|c|}
\hline Type of antibody & Antibody & $\begin{array}{c}\text { Fc } \gamma \text { RIIIa } \\
\text { MFI (\% } \\
\text { labeled } \\
\text { cells) }\end{array}$ & $\begin{array}{c}\text { FcyRIla } \\
\text { MFI (\% } \\
\text { labeled } \\
\text { cells) }\end{array}$ & $\begin{array}{c}\text { FcyRIIb2 } \\
\text { MFI (\% } \\
\text { labeled } \\
\text { cells) }\end{array}$ \\
\hline \multirow[t]{5}{*}{ NAb } & $2 \mathrm{G} 12$ & $185(93 \%)^{a}$ & 35 (84\%) & $85(83 \%)$ \\
\hline & $2 \mathrm{~F} 5$ & $133(48 \%)$ & $111(66 \%)$ & $164(64 \%)$ \\
\hline & 4E10 & 27 (35\%) & 18 (24\%) & ND \\
\hline & b12 & 62 (63\%) & $20(43 \%)$ & ND \\
\hline & LALA & $8(4 \%)$ & $10(5 \%)$ & ND \\
\hline \multirow[t]{3}{*}{ NoNAb (inhibitory) } & 246-D & 161 (95\%) & 73 (95\%) & $106(86 \%)$ \\
\hline & 4B3 & $17(36 \%)$ & $15(27 \%)$ & ND \\
\hline & F240 & ND & ND & ND \\
\hline NoNAb (noninhibitory) & b6 & 37 (65\%) & $23(40 \%)$ & ND \\
\hline
\end{tabular}

Fc $\gamma$ R, Fc $\gamma$ receptor; MFI, mean fluorescence intensity; NAb, neutralizing antibody; $\mathrm{ND}$, not done; NoNAb, nonneutralizing antibody.

Antibodies tested in vivo are indicated in bold.

${ }^{a}$ Each antibody was tested at least in two independent experiments. Representative data from one experiment are shown.

(Table 1). High and low Fc $\gamma$ Rs binders could be observed in the different groups of Abs. Both the 2G12 and 2F5 NAbs and 246$\mathrm{D}$ NoNAbs exhibited a strong binding to Fc $\gamma$ RIIIa. In addition, the 2G12 NAb and the 246-D NoNAb bound more moderately to $\mathrm{Fc} \gamma \mathrm{RIIa}^{+}$cells with lower mean fluorescence intensity as compared with the $2 \mathrm{~F} 5 \mathrm{NAb}$. The $4 \mathrm{E} 10$ and b12 NAbs, as well as the b6 NoNAb, bound weakly to Fc $\gamma \mathrm{RIIa}^{+}$cells but exhibited an intermediate binding to Fc $\gamma \mathrm{RIII}^{+}$cells (Table 1). Finally, the $4 \mathrm{~B} 3$ NoNAb showed the weakest binding to both Fc $\gamma \mathrm{RIIa}^{+}$ and Fc $\gamma \mathrm{RIIIa}^{+}$cells. As expected, the b12 LALA mutant did not bind any of the indicator cells. Competition experiments with an anti-Fc $\gamma$ RIII mouse $m A b$ (3G8) confirmed that the anti-PID $4 \mathrm{~B} 3$ binds Fc $\gamma$ RIII more weakly than the b6 and b12 mAbs. A
91\% 4B3 binding inhibition was obtained in the presence of $10 \mu \mathrm{g} \mathrm{ml}^{-1} 3 \mathrm{G} 8$, whereas only $7 \%$ and $18 \%$ binding inhibition was achieved at the same dose of 3G8 for the b12 and b6 mAbs, respectively. Similarly, an $85 \% 4 \mathrm{~B} 3$ binding inhibition was observed with $20 \mu \mathrm{g} \mathrm{ml}^{-1} 3 \mathrm{G} 8$, whereas $23 \%$ and $50 \%$ inhibition was obtained for b12 and b6 mAbs, respectively.

Thus, overall, no specific Fc $\gamma \mathrm{R}$ binding profile could be attributed to a peculiar type of Abs (NAbs or NoNAbs with distinct inhibitory activity).

\section{Ordering anti-HIV antibodies depending on their functional anti-HIV activities}

To get a more general view of the different in vitro inhibitory activities for each $\mathrm{Ab}$, a score representative of the anti-HIV activities was set up, and ranked in color codes (Figure 4). Highest score (eight boxes) was assigned for the neutralizing activity, surmising that this activity may be determinant for protection against HIV acquisition. As a consequence, NAbs cumulating other inhibitory activities in different assays have elevated final scores (black boxes). The b12 mutant LALA that retained the neutralizing activity but lacks Fc-mediated function had a total score below the parental b12 mAb. NoNAb b6 that had poor functional Fc-mediated inhibition scored even lower. However, some NoNAbs displayed an alternative profile, in particular the two anti-PID mAbs, 4B3 and 246-D. They showed good overall high inhibitory properties, despite the lack of neutralizing activity.

According to this in vitro score, we selected NoNAbs 246-D and 4B3 for efficacy testing against vaginal challenge in macaques. These were compared in parallel with the combination of the three NAbs: 2G12, 2F5, and 4E10.

Analysis of the glycosylation profile of antibodies selected for efficacy testing against vaginal challenge of macaques The pattern of Fc glycosylation influences Fc binding to Fc $\gamma$ Rs, and consequently may profoundly affect Fc effector functions. The glycosylation profiles of mAbs selected for in vivo trial in monkeys was therefore analyzed. Although 90-100\% fucosylation was detected on these mAbs (see Supplementary Figure S2 online), 4 of them (246-D, 4E10, 2F5, and 2G12) exhibited a marked binding to Fc $\gamma \mathrm{RIIIa}^{+}$cells (see above), whereas the other (4B3) showed a lower binding. $N$-Neuraminic acid was observed only on 4E10, 2F5, and 2G12 NAbs. Conversely, $\mathrm{N}$-Glycolylneuraminic acid was only detected on 246-D and 4B3 NoNAbs. However, the glycosylation profile of these highly fucosylated mAbs did not correlate with their ability to bind the various Fc $\gamma$ Rs (Table 1) or their capacity to inhibit HIV acquisition (Figure 4), suggesting that characteristics distinct from the Fc glycosylation profile contribute to the inhibitory functions of these Abs.

\section{Fc-mediated inhibition of HIV replication in macrophages by mAbs used in combination}

We determined whether combination of the two NoNAbs could be favorable for Fc-mediated inhibition in vitro. We observed a decrease of $\mathrm{IC}_{90}$ down to $0.04 \mu \mathrm{g} \mathrm{ml}^{-1}$ when 246-D and $4 \mathrm{~B} 3 \mathrm{mAbs}$ were used in combination, as compared with an $\mathrm{IC}_{90}$ of 0.2 and $0.9 \mu \mathrm{g} \mathrm{ml}^{-1}$ for $246-\mathrm{D}$ and $4 \mathrm{~B} 3$, respectively, 


\begin{tabular}{|c|c|c|c|c|c|c|c|c|}
\hline & \multirow{2}{*}{\multicolumn{6}{|c|}{ In vitro assay }} & \multirow{3}{*}{$\begin{array}{c}\text { In vivo } \\
\text { protection }\end{array}$} \\
\hline & & & & & & & & \\
\hline & & Neutralization & \multirow[t]{2}{*}{$M \Phi$} & \multirow{2}{*}{ ADCC } & \multirow[t]{2}{*}{ Capture } & \multirow[t]{2}{*}{$\mathrm{FcR}$} & \multirow[t]{2}{*}{ Final score } & \\
\hline \multirow{5}{*}{ NAbs } & $2 \mathrm{G} 12$ & & & & & & & \multirow{3}{*}{ Yes } \\
\hline & $2 \mathrm{~F} 5$ & & & & & & & \\
\hline & 4 E10 & & & & & & & \\
\hline & b12 & & & & & & & Yes: * \\
\hline & LALA & & & & & & & Partial \\
\hline \multirow{3}{*}{$\begin{array}{l}\text { NoNAbs } \\
\text { Inhibitory }\end{array}$} & 246-D & & & & & & & \multirow{2}{*}{ D-VL } \\
\hline & $4 \mathrm{~B} 3$ & & & & & & & \\
\hline & F240 & & & & & ND & & Partial/ D-VL* \\
\hline Nonlnhibitory & b6 & & & & & & & No* \\
\hline
\end{tabular}

Figure 4 Inhibitory profile of monoclonal antibodies (mAbs). For each in vitro inhibition of infection or binding, the activity detected was scored and visualized by boxes with increasing numbers and color intensities. Eight boxes were attributed to neutralizing activity, considered to be the foremost activity associated with in vivo protection. The activities were summed for each mAb by recording the number of positive boxes (from gray to dark color) to obtain the overall inhibitory profile of each Ab. Neutralization: as measured in Figure 1a; M $\Phi$ : Fc-mediated inhibition as measured in Figure 1b; antibody-dependent cellular cytotoxicity (ADCC) as measured in Figure 2; capture as measured in Figure 3; Fc $\gamma$ R as measured in Table 1. Total score correspond to the sum of the positive boxes of each in vitro assay. Last column summarizes in vivo protection in macaque model. *Hashed colored boxes correspond to in vivo data published by Burton et al. ${ }^{6} \mathrm{Fc} \gamma \mathrm{R}, \mathrm{Fc} \gamma$ receptor; M $\Phi$, macrophage; NAb, neutralizing antibody; ND, not done; NoNAb, nonneutralizing antibody; VL, viral load.
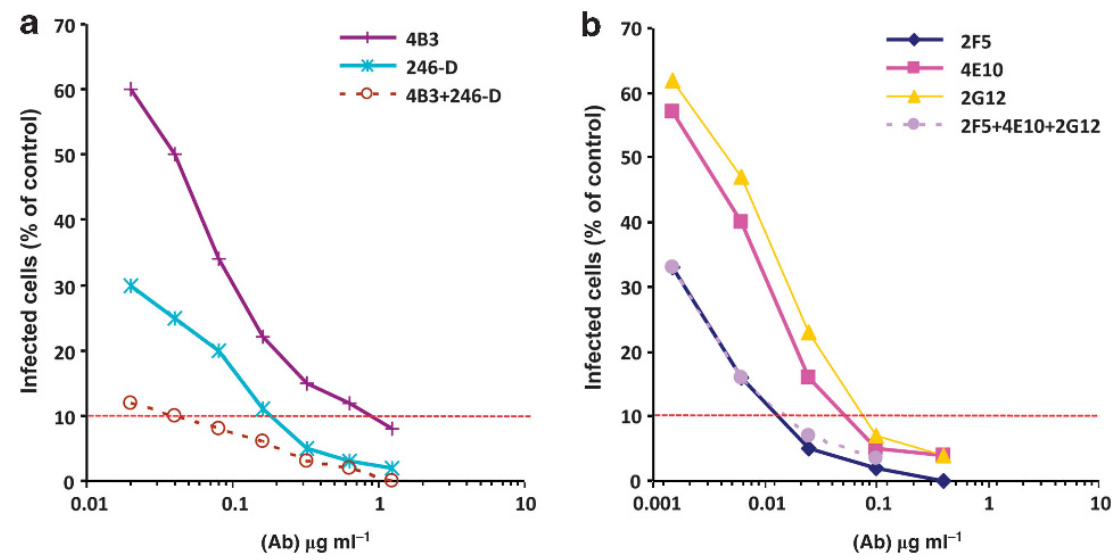

Figure 5 Fc-mediated inhibition by neutralizing or inhibitory monoclonal antibodies (mAbs). (a) Anti-PID 246-D and 4B3 nonneutralizing antibodies (NoNAbs) or (b) 2G12, 2F5, and 4E10 neutralizing antibodies (NAbs) were tested alone or in combination to evaluate their Fc-mediated inhibitory activity on HIV replication. PID, principal immune-dominant domain. The $\mathrm{IC}_{90}$, i.e., concentration of $\mathrm{mAb}$ able to decrease by $90 \%$ the percentage of infected cells, was defined (dotted red line).

when tested alone (Figure 5). This increased inhibitory activity was found synergistic according to the Chou and Talalay calculation (combination index <0.4). ${ }^{26}$ In contrast, no increased Fc-mediated inhibition was obtained when the three NAbs were combined, compared with $2 \mathrm{~F} 5 \mathrm{mAb}$ alone. The $\mathrm{IC}_{90}$ for $2 \mathrm{~F} 5 \mathrm{mAb}$ was approximately one log lower than that of $2 \mathrm{G} 12$ and $4 \mathrm{E} 10 \mathrm{mAbs}$, thus explaining the lack of impact of $2 \mathrm{G} 12$ and $4 \mathrm{E} 10 \mathrm{mAbs}$ on the high inhibitory activity of $2 \mathrm{~F} 5$ $\mathrm{mAb}$. It is noteworthy that the $\mathrm{IC}_{90}$ of Fc-mediated inhibitory activity on macrophages of the 246-D and $4 \mathrm{~B} 3$ NoNAb combination was of the same order of magnitude as for the three NAbs used in combination or for mAb $2 \mathrm{~F} 5$ alone.

\section{Relevance of NHPs for in vivo testing of neutralizing and anti-PID inhibitory activity}

SHIVSF162P3 was selected to assess the activity of NAbs and anti-PID Abs in in vivo challenge studies. This virus is of Tier-2 and more resistant to neutralization than parental HIV1SF162. Using the TZM-bl-based assay, the combination of
NAbs 2F5, 4E10, and 2G12 neutralize SHIVSF162P3 with an average $\mathrm{IC}_{50}$ of $97(90-103) \mathrm{ng} \mathrm{ml}^{-1}(n=2)$. Using the same assay, the TriMab combination has a very similar activity on HIV-1 SF162 ( IC $_{50}$ of $\left.41-43 \mathrm{ng} \mathrm{ml}^{-1}\right)$. Fc-mediated inhibitory activity of NoNAbs was also tested on macaque macrophages. As for human cells, anti-PID human mAbs inhibit SHIV infection of macaque macrophages. Infection of macaque MDMs with the R5 chimerical SHIVBx08 (see ref. 27) was decreased by $71 \%$ in the presence of $10 \mu \mathrm{g} \mathrm{ml}^{-1}$ of mAb 246-D (Supplementary Figure S3 online). At this concentration, virus production was also decreased at 10 days (from 0.33 to $0.013 \mathrm{ng} \mathrm{ml}^{-1}$ of $\mathrm{p} 27$ antigen). Blockade of SHIVSF162P3 could not be assessed because of its poor replicative capacity on macaque MDMs in in vitro assays.

\section{Prevention of the vaginal transmission of SHIVSF162P3 by anti-HIV-1 mAbs in NHPs}

To assess the specific role of anti-HIV Abs present at the mucosal surface, regardless of the associated activities in other 


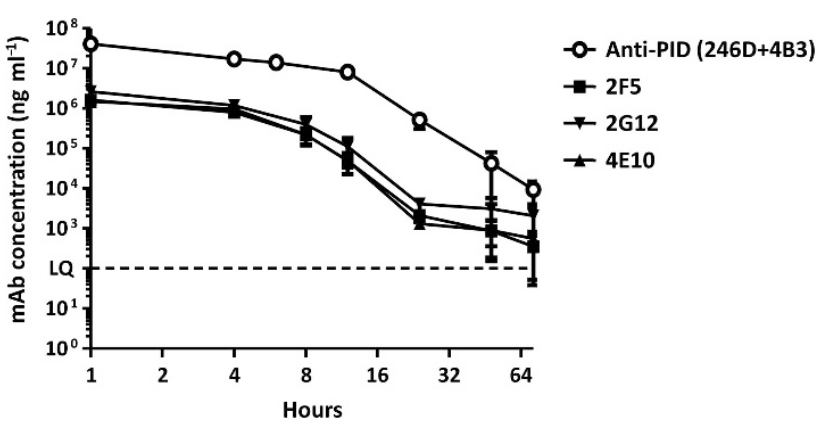

Figure 6 Persistence of antibodies (Abs) in vaginal fluids collected at several time points after vaginal application of $1.6 \%$ hydroxyethyl cellulose (HEC) gel containing a combination of neutralizing antibodies (NAbs; filled symbols) or anti-PID Abs (nonneutralizing antibodies (NoNAbs) (empty symbol). Curve of 246-D and 4B3 (application of $60 \mathrm{mg} \mathrm{ml}^{-1}$ of the 246-D and 4B3 monoclonal antibody (mAb) combination) therefore correspond to threefold the concentration of each of the three NAbs ( 3 times $20 \mathrm{mg} \mathrm{ml}^{-1}$ of each neutralizing mAb). PID, principal immune-dominant domain.

compartments, including blood, we directly applied in the vaginal vault the two selected $\mathrm{Ab}$ combinations loaded into a $1.6 \%$ hydroxyethyl cellulose gel $(2 \mathrm{ml})$. Optimal dosing and time of SHIVSF162P3 challenge were defined according to retention studies after vaginal application of Abs.

For the pharmacokinetic study, Depo-Provera pretreated macaques were treated with the gel containing a combination of neutralizing $(n=6)$ or anti-PID $(n=2)$ Abs. At different time points, $\mathrm{Ab}$ concentrations were measured in cervicovaginal fluids by antipeptide or total protein enzyme-linked immunosorbent assay (ELISA). At a dose of $20 \mathrm{mg}$ of each of the 4E10, $2 \mathrm{G} 12$, and $2 \mathrm{~F} 5 \mathrm{NAbs}$ per $\mathrm{ml}$ of gel $\left(60 \mathrm{mg} \mathrm{ml}^{-1}\right.$ in total), vaginal fluids collected between 1 and $8 \mathrm{~h}$ after treatment contained $\mathrm{Ab}$ concentrations above the anti-HIV SF162 IC $_{50}$ $\left(6 \mu \mathrm{g} \mathrm{ml}^{-1}\right)$ in TZM-bl assay (Figure 6 and Supplementary Table S1 online). Vaginal fluids collected $1 \mathrm{~h}$ after treatment with $30 \mathrm{mg} \mathrm{ml}^{-1}$ of each of the $4 \mathrm{~B} 3$ and $246-\mathrm{D} \mathrm{mAbs}$ $\left(60 \mathrm{mg} \mathrm{ml}^{-1}\right.$ in total) also retained concentrations compatible with macrophage inhibitory activities measured in vitro (Figure 6 and Supplementary Table S2 online). This concentration corresponds to the sum of $246-\mathrm{D}+4 \mathrm{~B} 3$ as these two Abs recognizing closely linked epitopes ${ }^{28,29}$ could not be discriminated by ELISA. Levels of mAb concentrations in serum at the same time points remained below detection limits (40 $\mathrm{ng} \mathrm{ml}^{-1}$ ).

For the vaginal challenge study, Depo-Provera pretreated females were subjected to a single vaginal application $(2 \mathrm{ml})$ of hydroxyethyl cellulose gel containing no $\mathrm{Ab}$ (placebo, $n=18$ ) or the combination of NAbs $2 \mathrm{G} 12,2 \mathrm{~F} 5$ and $4 \mathrm{E} 10 \mathrm{mAbs}$ or NoNAbs anti-PID 246-D and 4B3. Animals were then challenged $1 \mathrm{~h}(n=9$ for NAb combination and $n=6$ for NoNAb combination) or $4 \mathrm{~h}$ ( $n=6$ for the NAb combination) after treatment with a high dose $\left(\sim 4-10 \quad \mathrm{AID}_{50}\right)$ of SHIVSF162P3. This virus expressed the R5-clade B envelope of HIV-1SF162 and was produced on macaque PBMCs after three in vivo passages in macaques. ${ }^{30,31}$
Efficient protection from acquisition of SHIV infection was obtained with the combination of NAbs only and with equal efficacy at $1 \mathrm{~h}\left(66 \%, \chi^{2} P=0.038\right)$ and $4 \mathrm{~h}\left(70 \%, \chi^{2} P=0.037\right)$ after challenge (Figure 7). Protection in treated animals could not be attributed to major histocompatibility complex (MHC) protective alleles (see Supplementary Figure S4 online), low local $\mathrm{Ab}$ concentrations, or selection of resistant virus. Measurement of residual local $\mathrm{Ab}$ concentration collected on Weck-Cel sponges at $24 \mathrm{~h}$ after challenge did not demonstrate differences between protected and nonprotected macaques (Mann-Whitney test, $P=0.77$, Supplementary Figure S5 online). Virus isolated at day 14 after challenge in treated and nontreated animals was still susceptible to neutralization by the $2 \mathrm{G} 12,2 \mathrm{~F} 5$, and $4 \mathrm{E} 10$ combination with the same $\mathrm{IC}_{50}$ value. In addition, residual plasma concentrations of 2F5 and 4E10 did not appear to affect the initial control of viremia as plasma viral load at day 14 after infection (Figure 7) in animals pretreated with NAbs $(-1 \mathrm{~h}$ and $-4 \mathrm{~h}$ groups) did not differ from controls (Mann-Whitney test, $P=0.307$ and $P=0.148$, respectively). Therefore, the absence of protection of some animals should be probably attributed to nonidentified technical issues or to statistical risk of infection in the presence of NAbs.

The combination of anti-PID mAbs did not prevent SHIVSF162P3 vaginal transmission (Mann-Whitney test, $P=0.98$, Figure 7) suggesting that neutralizing activity is certainly key to blockade of SHIV infection at the mucosal portal of entry. Interestingly, three different kinetic patterns of viral load were observed in anti-PID-treated animals: three animals behaved as controls, one animal had a delayed peak of viremia (day 22), and two animals had blunted infections of short duration and lower peak viremia relative to infected controls (Figure 7e, $P=0.1158$, Mann-Whitney test with Bonferroni adjustment as one control group is common for three treated groups). These observations suggest that although unable to block virus entry at mucosal sites, in $50 \%$ of treated animal, these Abs affected subsequent viral replication and dissemination through other effector mechanisms. Of note, Fc-mediated inhibition in vaginal fluids $24 \mathrm{~h}$ after challenge in macaques treated with anti-PID mAbs did not correlate with day 14 plasma viremia. It was approximately one order of magnitude (Table 2) lower than that detected in samples collected after treatment with NAbs combination, although both combinations were at similar concentrations $\left(60 \mathrm{mg} \mathrm{ml}^{-1}\right)$ and had similar inhibitory activities in vitro (Figure 4).

\section{DISCUSSION}

The potential correlation of many in vitro assays analyzing $\mathrm{mAb}$ functionalities with in vivo protection against HIV infection and/or AIDS progression has not yet been established. In this study, we analyzed various HIV inhibitory activities of neutralizing and nonneutralizing mAbs. We scored these activities to obtain a more general overview of their in vitro functionalities (Figure 4). We found that NAbs cumulated numerous inhibitory functions that might be critical for in vivo 

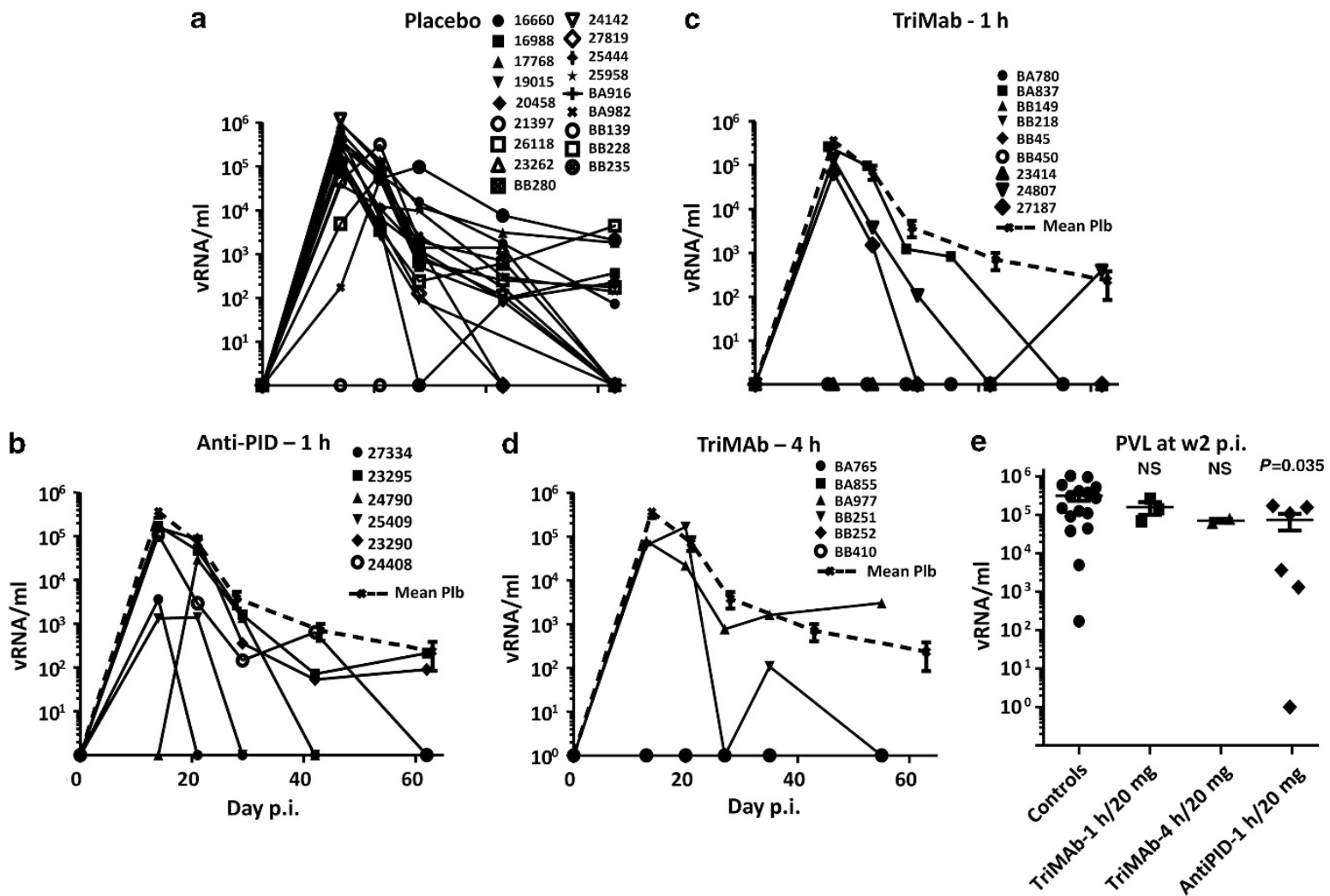

Figure 7 Plasma viral load in SHIVSF162P3-challenged macaques. Animals were treated with (a) placebo $1 \mathrm{~h}$ before challenge or (b) hydroxyethyl cellulose (HEC) gel containing the combination of anti-PID antibodies (Abs) $1 \mathrm{~h}$ before challenge, or the combination of 2F5, 4E10, and 2G12 Abs (c) $1 \mathrm{~h}$ (TriMab $1 \mathrm{~h}$ ) or (d) $4 \mathrm{~h}$ before challenge (TriMab $4 \mathrm{~h}$ ). (e) Plasma viral load of infected animals in all groups 2 weeks (w2) after simian/human immunodeficiency virus (SHIV) challenge. NS, not significant; p.i., post-infection; PID, principal immune-dominant domain.

protection. Interestingly, despite having no neutralizing activity on primary $\mathrm{CD} 4^{+} \mathrm{T}$ lymphocytes, some NoNAbs demonstrated broad and potent ADCC and Fc-mediated inhibitory activities (Figure 4) in agreement with previous reports. ${ }^{13,18}$ NoNAbs $246-\mathrm{D}$ and $4 \mathrm{~B} 3 \mathrm{mAbs}$ displayed different inhibitory functions that contributed to a high total inhibitory score (Figure 4). These mAbs recognize the PID of gp41, a highly immunodominant epitope. Abs directed against this epitope can be induced more easily by vaccination than NAbs. This epitope is relatively conserved among types and subtypes and easily accessible on virions. ${ }^{11}$ Thus, anti-PID Abs can efficiently capture a broad range of HIV strains ${ }^{21}$ and consequently may limit mucosal penetration.

The in vitro nonneutralizing inhibitory activity studied has potential to contribute to protection from sexual transmission. At a mucosal portal of entry, dendritic cells and macrophages are highly prevalent and may be actively involved in HIV infection and subsequent rapid dissemination to draining lymph nodes. Thus, anti-PID mAbs that bind to Fc $\gamma$ Rs and to virus particles and induce Fc-mediated inhibitory activity on antigen-presenting cells might be relevant for prevention of sexual HIV transmission. In addition, infection of $\mathrm{CD}^{+}{ }^{+} \mathrm{T}$ cells may rapidly result in local inflammation and attract NK cells that may selectively lyse infected $\mathrm{T}$ cells, either by natural cytotoxicity or through ADCC induced by NoNAbs.
Involvement of Fc-mediated inhibition following human $\mathrm{mAb}$ transfer has been previously demonstrated by b12 mutant LALA. ${ }^{3}$ Indeed, IgG1 from human or macaque origin showed identical $\mathrm{Fc} \gamma \mathrm{R}$ interaction and ADCC effector function profile in both human and NHP cells. ${ }^{32}$ We further demonstrated that the Fc-mediated inhibitory activity of human IgG1 was conserved on macaque MDMs, suggesting that local vaginal application of 246-D +4B3 NoNAbs followed by vaginal challenge in the macaque model may recapitulate the different potential Fc-mediated inhibitory mechanisms. However, we could not ascertain that the potency of inhibition by the antiPID human mAbs was fully preserved in NHP as mAbs from macaque origin with similar activities were not available. Similarly, use of Fc $\gamma \mathrm{R}$-expressing cell lines may not recapitulate the affinity and accessibility of human Abs to receptors on primary effector cells of human origin. Also, targeting macaque primary cells with immunoglobulins containing human Fc may not fully mimic the natural situation in humans, limiting the relevance of the NHP to model these interactions. This may explain the lack of correlation between in vitro tested antiviral activity $^{33}$ and protection in vivo. ${ }^{34}$

Combinations of either NAbs $(2 \mathrm{G} 12+2 \mathrm{~F} 5+4 \mathrm{E} 10)$ or NoNAbs (246-D + 4B3) were applied locally before the vaginal challenge with a single high dose of SHIVSF162P3. Prevention from transmission of SHIV (70\%) was achieved by the 
Table 2 Fc-mediated inhibitory activity in Weck-Cel recovered 1 day after challenge

\begin{tabular}{llll}
\hline $\begin{array}{l}\text { Weck } \\
\text { cells }\end{array}$ & $\begin{array}{l}\text { Concentration } \\
\text { 4B3 }+246-\mathrm{D} \mu \mathrm{g} \mathrm{m}^{-1}\end{array}$ & $\begin{array}{l}\text { Viral load } \\
\text { day 14 after } \\
\text { infection }\end{array}$ & $\begin{array}{l}\text { Inhibition } \\
\text { macrophage/ } \\
\text { SF162 IC }\end{array}$ \\
\hline
\end{tabular}

HEC gel

26118

23262

24142

27819

25444

25958

\section{0}

$5.00 E+05$

$<10$

$<10$

$5.00 \mathrm{E}+05$

$<10$

$5.00 \mathrm{E}+05$

$<10$

$5.00 \mathrm{E}+05$

$<10$

0

$5.00 \mathrm{E}+05$

$<10$

NoNAbs 246-D + 4B3

$\begin{array}{rrlr}27334 & 115 & 3.00 \mathrm{E}+03 & 10 \\ 23295 & 95 & 1.00 \mathrm{E}+05 & 10 \\ 24790 & \mathrm{ND} & \text { Delayed viral load } & <10 \\ 25409 & 110 & 1.00 \mathrm{E}+03 & 90 \\ 23290 & 795 & 1.00 \mathrm{E}+05 & 90 \\ 24408 & 110 & \text { Early decrease VL } & 90\end{array}$

NAbs $2 F 5+4 E 10+2 G 12$

\begin{tabular}{lrlr}
23414 & 0 & Protected & 900 \\
24807 & 0 & $5.00 E+05$ & 150 \\
27183 & 0 & $1.00 E+05$ & 300 \\
BA780 & ND & Protected & ND \\
BA837 & ND & $1.00 E+05$ & ND \\
BB149 & ND & Protected & ND \\
BB218 & ND & $1.00 E+05$ & ND \\
BB45 & ND & Protected & ND \\
BB450 & ND & Protected & ND \\
\hline
\end{tabular}

$\overline{\mathrm{HEC} \text {, hydroxyethyl cellulose; } \mathrm{IC}_{80}, 80 \% \text { inhibitory concentration; NAb, neutralizing }}$ antibody; ND, not done; NoNAb, nonneutralizing antibody; VL, viral load.

FC-mediated inhibition of HIV replication in macrophages infected with HIV-1 SF162 was analyzed in Weck-Cel collected 1 day following vaginal challenge. The percentage of monocyte-derived macrophages (MDMs) infected in the presence or absence of successive dilution of Weck-Cel was measured. The inverse of the dilution of Weck-Cel resulting in $80 \%$ decrease in the percentage of infected cells was calculated and reported. In parallel, viral load detected at peak of infection was reported. The decreased viral load was not correlated with the in vitro Fc-mediated inhibitory activity detected in Weck-Cel collected 1 day following challenge.

combination of a high dose of the three NAbs. In a previous study, local application of a single mAb b12 at a lower concentration of $5 \mathrm{mg}$ was unable to protect against this challenge virus. ${ }^{6}$ These results suggest that effective prevention likely requires complete blockade of HIV infection of $\mathrm{CD} 4^{+} \mathrm{T}$ lymphocyte targets. Confirming this hypothesis, we recently reported that a small peptide competing with $\mathrm{CD} 4$ through binding to gp120 CD4 also efficiently prevent SHIV mucosal transmission. ${ }^{35}$ The observed protection would likely be further improved with combinations of newer generation of very potent, broadly neutralizing Abs, where their increased potency might allow for dose-sparing effects. ${ }^{36}$
Interestingly, although not preventing infection, a modest decrease in viral load was observed in several of the animals treated with anti-PID mAbs, suggesting that other $\mathrm{Ab}$ functionalities, beside neutralization, may contribute to virus control.

Of note, Burton et al. ${ }^{6}$ described a similar decreased viral load for another NoNAb anti-PID, F240, tested in vitro herein. Vaginal application of F240 at $30 \mathrm{~min}$ before vaginal challenge with the more sensitive to neutralize SHIVSF162P4 protected two animals, and decreased viral load in two out of the five treated macaques. This $\mathrm{Ab}$ displayed an overall in vitro inhibitory activity comparable to $246-\mathrm{D}$ and $4 \mathrm{~B} 3 \mathrm{mAbs}$ (Figure 4). In contrast, the $\mathrm{b} 6 \mathrm{mAb}$ did not lead to protection ${ }^{6}$ and obtained a poor total score in our in vitro inhibitory assays (Figure 4). Therefore, characterization of mAbs according to their multiple functional inhibitory activities may help in predicting their in vivo protective effect and design new strategies to prevent HIV transmission. Thus, further studies are now warranted to define correlates between in vitro $\mathrm{Ab}$ effector functions and in vivo protection. The scoring proposed here for the characterization of $\mathrm{Ab}$ functions is not exhaustive, but it represents the first attempt to systematize approaches. Additional inhibitory functions may need to be evaluated, such as complement-mediated inhibition ${ }^{37,38}$ or antibodydependent cell-mediated virus replication inhibition that comprise ADCC and additional functions, including cytokine production. ${ }^{8,39}$

A number of potential limitations that may have affected the efficacy of treatment should be taken into consideration. Local application may not be optimal to achieve high local $\mathrm{Ab}$ concentration within the localized mucosa. Indeed, although we observed $70 \%$ protection from infection, previous passive infusion of NAbs provided complete protection. ${ }^{40-42}$ Thus, it would be interesting to determine if the modest impact of the evaluated NoNAbs could be increased following passive infusion where increased concentrations within the mucosa offer the potential for more effective ADCC. More recent studies have suggested $\mathrm{pH}$-dependent localized IgG transport by the Fc neonatal receptor. ${ }^{43}$ This may be more active in women where vaginal $\mathrm{pH}$ is more acidic than that of macaques. Thus, potential antibody uptake could have been underestimated in this model. Nevertheless, Fc neonatal receptor uptake may also have possible drawbacks should it lead to NoNAb transfer of infectious virions across mucosal surfaces.

Finally, the protocol using Depo-Provera treatment, reflective of the progesterone-dominated luteal phase of the menstrual cycle, may not be particularly favorable for analyzing Fc-mediated inhibition. This treatment facilitates virus transmission by thinning the vaginal epithelium. This may increase direct access to $\mathrm{CD} 4^{+}$T lymphocytes, bypassing the potential antiviral activity of Langerhans cells, interstitial dendritic cells, and macrophages that predominate during the follicular phase.

Despite these limitations, our results demonstrate that NAbs have potential interest for microbicide and vaccine development. In addition, inhibitory functions suggested by 
our study for nonneutralizing anti-PID Abs may complement or synergize with the protective effect of NAbs. Further studies are now required to determine whether combining Abs with different effector functions could provide further gains in protective efficacy.

\section{METHODS}

Antibodies and viruses. The 2G12, 2F5, and $4 \mathrm{E} 10$ NAbs were obtained from Polymun Scientific, GmbH (Klosterneuburg, Austria). The b12 NAb, its LALA mutant counterpart, and the $\mathrm{b} 6 \mathrm{mAb}$ were kindly provided by Professor D. Burton (The Scripps Research Institute, La Jolla, CA). The mAbs against gp41 were kindly provided by Professor S. Zolla-Pazner (246-D) and Polymun (4B3, 3D6), respectively. The F $240 \mathrm{mAb}$ was obtained from the AIDS Research and Reference Reagent Program (Division of AIDS, NIAID, NIH, Bethesda, MD). The anti-RSV mAb Synagis (palivizumab, Medimmune, Gaithersburg, MD) was used as control mAb. Antibodies used for challenge experiments were manufactured by Polymun Scientific GmbH. Shortly, nAbs 2G12, 2F5, and 4E10 were expressed in Chinese hamster ovary cells as human IgG1 (k). ${ }^{29,44}$ NoNAbs anti-PID 246-D IgG1 $(\mathrm{k})$ and 4B3 (IgG1 $(\lambda)$ were expressed in hybridoma cells. Fermentation was performed as fed batch culture. Purification included protein A affinity chromatography and a polishing step. These human IgG1 mAbs were tested for in vitro inhibitory activity in different assays described below except for the TZM-bl assay and glycosylation profile, performed only on the mAbs selected for in vivo studies.

For in vitro studies of Ab inhibitory activities, HIV-1 SF162 (obtained from the AIDS Research and Reference Reagent Program, Division of AIDS, NIAID, NIH) and SHIVBx08 (ref. 27) were used.

Neutralization assays and Fc-mediated inhibition of HIV replication in MDMs. Neutralization assays using PBMCs as target cells were performed in parallel to Fc-mediated inhibitory assays on MDMs as previously described by Holl et al. ${ }^{16,17}$ Briefly, unless otherwise stated, PBMCs and MDMs were purified, cultured, and differentiated from human HIV-1-seronegative blood donors. In some experiments, PBMCs were purified from blood of cynomolgous macaques and cynomolgous MDMs were generated using experimental condition as previously described. ${ }^{16,17} \mathrm{Abs}$ and virus were incubated for $1 \mathrm{~h}$ before addition of either phytohemagglutinin-activated PBMCs (neutralization) or MDMs (Fc-mediated inhibition). Virus replication was measured after $48 \mathrm{~h}$ by the intracellular staining of p24 in CD3 ${ }^{+}$ T lymphocytes or MDMs by flow cytometry. The percentage of infected cells compared with control infected cells without mAbs was determined.

Antibody-dependent cellular cytotoxicity. $\mathrm{CD}^{+}{ }^{+}$-enriched $\mathrm{T}$ cells were obtained after depletion of NK cells and $\mathrm{CD} 8{ }^{+} \mathrm{T}$ lymphocytes from PBMCs with anti-CD56 and anti-CD8 Ab-coated magnetic beads (AutoMacs) (Miltenyi Biotec, Cologne, Germany), respectively. The cells were infected with HIV-1 SF162 primary isolate for $96 \mathrm{~h}$. Various concentrations of mAbs were added to $50 \mu \mathrm{l}$ of infected $\mathrm{CD}^{+}{ }^{+}$-enriched T cells at $8 \times 10^{6}$ cells per $\mathrm{ml}$ in RPMI-1640, $10 \%$ fetal calf serum, and 50 IU interleukin-2 (R\&D System, Minneapolis, MN). After $30 \mathrm{~min}$ of incubation at $37^{\circ} \mathrm{C}, 50 \mu \mathrm{l}$ of autologous NK cells were added (ratio 1:1) and further incubated for $16 \mathrm{~h}$. In order to exclude nonviable cells from subsequent analyses, the cells were stained using the Live/Dead Fixable Dead Cell Stain fluorescence Kits (Invitrogen Life Science, Applied Biosystems, Saint-Aubin, France). Target and effector cells were distinguished by membrane staining using CD3VioBlue (Miltenyi Biotec), CD16-PhycoerythrinCyan5 (PECy5), and CD56-Allophycocyanin from Becton Dickinson (BD) Biosciences (San Jose, CA). Cells were then fixed and permeabilized (Cytofix/ cytoperm; BD Biosciences) and stained for intracellular p24 (KC57RD1) to detect infection. Percentage of target cell lysis was calculated as ((\%p24 infected target cells with effectors - \%p24 infected target cells with effectors and $\mathrm{mAb}) \div \%$ p 24 infected targets with effectors) $\times 100$.

Anti-HIV antibody binding to Fc $\gamma \mathbf{R s}$. The binding of $\mathrm{mAbs}$ to the different $\mathrm{Fc} \gamma$ Rs was assessed by an indirect immunofluorescence assay using either MDMs or cells expressing solely one given Fc $\gamma$ R (TZM-bl 5028 (Fc $\gamma \mathrm{RI}$ ), Jurkat-CD16 (Fc $\gamma$ RIIIa), K562 (Fc $\gamma$ RIIa), and IIA1.6IIb2 (Fc $\gamma$ RIIb2)) as previously described. ${ }^{24,25}$ Briefly, cells were incubated with different concentrations $\left(10,5,1\right.$, and $\left.0.5 \mu \mathrm{g} \mathrm{ml}^{-1}\right)$ of mAbs for $1 \mathrm{~h}$ at $4{ }^{\circ} \mathrm{C}$, washed, and incubated for $1 \mathrm{~h}$ at $4{ }^{\circ} \mathrm{C}$ with $\mathrm{F}\left(\mathrm{ab}^{\prime}\right)_{2}$ goat anti-human $\operatorname{IgG}(\mathrm{H}+\mathrm{L})$-Phycoerythrin (PE) (1:250) (Beckman-Coulter, Fullerton, CA).

In other experiments, Fc $\gamma$ RIII was first blocked by incubation with a mouse anti-Fc $\gamma$ RIII (3G8) $\mathrm{mAb}$ (BD Pharmingen) at 10 or $20 \mu \mathrm{g} \mathrm{ml}^{-1}$ for $1 \mathrm{~h}$ at $4^{\circ} \mathrm{C}$ before addition of $\mathrm{mAbs} 4 \mathrm{~B} 3$, b6, and b12 $\left(10 \mu \mathrm{g} \mathrm{ml}^{-1}\right)$. After $1 \mathrm{~h}$ of incubation at $4{ }^{\circ} \mathrm{C}, \mathrm{mAb}$ binding in the presence or absence of $3 \mathrm{G} 8$ was detected. The binding inhibition (\%) was calculated using the mean fluorescence intensity obtained with anti-HIV mAbs incubated with indicator cells (Jurkat-CD16 (FcyRIIIa)) in the absence of anti-Fc $\gamma$ RIII Ab as reference. In all the experiments, cells were washed and fixed with $0.5 \%$ formaldehyde and samples were acquired on the LSRII cytometer (BD) and analyzed using the FACS Diva software (BD).

Glycosylation analysis. Glycosylation was evaluated by comparison of the liquid chromatography electrospray ionization-mass spectroscopy obtained on tryptic glycopeptide TKPREEQYNSTYR from 4B3 and 246-D NoNAbs, and 4E10, 2F5, and 2G12 NAbs after tryptic digestion. Briefly, the tryptic digests were analyzed by $\mathrm{C} 18$ reversed phase on a nanoACQUITY Ultra-Performance-LC system coupled to a SYNAPT Q-Tof (Waters, Milford, MA) mass spectrometer. Combined spectra corresponding to the area of glycopeptides elution of 4B3, 246-D, 4E10, 2F5, and 2G12 mAbs were analyzed.

Capture of free viral particles by mAbs. The assay measures the concentration of whole native virus particles captured by mAbs coated onto 96-well plates (Maxisorp, Nunc, Rocksilde, Denmark) as previously described. ${ }^{21,45}$ Briefly, HIV infectious particles were incubated in $\mathrm{mAb}$-coated ELISA plates for $1 \mathrm{~h}$. Unbound virus was removed by washing with phosphate-buffered saline containing $10 \%$ fetal calf serum. Virus captured by mAbs was lysed with $10 \% \mathrm{NP}-40$ and quantified by dosage of p24 by ELISA (Innogenetics/Ingen, Ghent, Belgium).

Evaluation of HIV-1 SF162 and SHIVSF162 sensitivity to the mixture of $2 \mathrm{G} 12+\mathbf{2 F 5}+\mathbf{4 E} 10$ in TZM-bl assay. Primary HIV-1 SF162 or SHIVSF162P3 were briefly amplified in phytohemagglutinin/interleukin-2 activated human PBMCs. The inhibitory activity of the $2 \mathrm{G} 12+2 \mathrm{~F} 5+4 \mathrm{E} 10 \mathrm{mAb}$ mixture against the primary HIV-1 SF162 and SHIVSF162P3 was measured on TZM-bl cells as previously described. ${ }^{46}$ The inhibitory activity was calculated with GraphPad Prism 5.03 using nonlinear regression (GraphPad Software, San Diego, CA).

NHP studies. Adult cynomolgus macaques (Macaca fascicularis) were imported from Mauritius and housed in the facilities of the "Commissariat à l'Energie Atomique et aux Energies Alternatives" (CEA, Fontenay-aux-Roses, France). NHPs are used at the CEA in accordance with the French national regulation (CEA Permit Number A 92-032-02). The CEA is in compliance with Standards for Human Care and Use of Laboratory of the Office for Laboratory Animal Welfare (OLAW, USA) under OLAW Assurance number A5826-01. The use of NHPs at CEA is also in accordance with the recommendation of the newly published European Directive (2010/63, recommendation no. 9). No suffering was specifically associated with the vaginal treatment of macaques. This study was approved by the ethical committee "Comité Régional d'Ethique pour l'Expérimentation Animale Ile-de-France Sud" under statement number 04001 of 7 April 2004. 
Pharmacokinetic studies. For the pharmacokinetic study, two $2 \mathrm{ml}$ of $1.6 \%$ hydroxyethyl cellulose gel containing $20 \mathrm{mgg}^{-1}$ of each of the NAbs $\left(60 \mathrm{mgg}^{-1}\right.$ in total) or $30 \mathrm{mgg}^{-1}$ of each NoNAb $\left(60 \mathrm{mgg}^{-1}\right.$ total) were injected into the vaginal vault of naive females using a French catheter connected to ready-to-use syringe. Vaginal fluids were sampled using Weck-Cel Spears, (Medtronics, Fridley, MN) before and 1, 4, 6, 24, 48 and $72 \mathrm{~h}$ after gel application.

$\mathrm{Ab}$ concentrations at each sampling were evaluated by ELISA. Briefly, GGGLELDKWASL and the KKWNWFDITNWGGG peptides were coated onto 96-well microtiter plates for 2F5 and $4 \mathrm{E} 10 \mathrm{mAb}$ studies, respectively. For $2 \mathrm{G} 12 \mathrm{mAb}$ detection, gp160 protein was used for coating. As 246-D and 4B3 NoNAbs recognize a similar linear PID epitope, ${ }^{28,29}$ a single PID peptide (ARP 7022, NIBSC, Blanche Lane, Potters Bar, UK) was used for coating to quantify the concentration of these two mAbs. Standard and samples were run in parallel. After incubation for $1 \mathrm{~h}$ at room temperature and washing with phosphate-buffered saline $\mathrm{pH} 7.2$ containing $0.1 \%$ Tween 20, horseradish peroxidase-conjugated goat anti-human IgG (Fc $\gamma$ ) Abs (Zymed Laboratories, South San Francisco, CA) were added. After incubation for $1 \mathrm{~h}$ at room temperature and washing, the chromogene substrate $o$-phenylenediamine dihydrochloride and $\mathrm{H}_{2} \mathrm{O}_{2}$ were added. The reaction was stopped with $2.5 \mathrm{M}$ sulfuric acid. The absorbance was measured at $492 \mathrm{~nm}$ (reference wavelength $620 \mathrm{~nm}$ ) and the results evaluated with a fourth-degree polynomial (Software Biolise for Windows, Labtech, East Sussex, UK).

Efficacy trial. Naive cynomolgus macaque females, treated with $30 \mathrm{mg}$ depo-medroxyprogesterone acetate (Depo-Provera, Pfizer, New York, NY) 30 days before challenge, were used for efficacy trials. Placebo or mAb-loaded gels were nontraumatically injected into the vaginal vault 1 or $4 \mathrm{~h}$ before challenge. Intravaginal challenge was carried out with $\sim 10$ AID50 (50\% animal infectious dose) of SHIVSF162P $3,{ }^{31}$ inoculated in $50 \%$ human seminal plasma. ${ }^{47}$

Plasma viremia was evaluated as previously described using quantitative reverse transcriptase-PCR for the measurement of viral RNA copy numbers. The detection limit of this method is 60 RNA copies/ml and quantification limit is $300 \mathrm{RNA}$ copies $/ \mathrm{ml}^{47}$ The SHIV DNA copy numbers in lymph nodes were also measured in animals with undetectable plasma viremia by quantitative PCR, using primers amplifying the gag regions of SHIV. Detection limit was 10 copies per million of cells. Because of small size of experimental groups, we have used nonparametric tests for comparison of viral load. MHC haplotypes were determined by microsatellite analysis. $^{48}$

SUPPLEMENTARY MATERIAL is linked to the online version of the paper at http://www.nature.com/mi

\section{ACKNOWLEDGEMENTS}

We thank Sylvie Schmidt, Géraldine Laumond, Thomas Decoville, and Mélanie Lambotin from the INSERM U.748; Patricia Brochard, Naya Sylla, Benoit Delache, and the TIPIV staff at CEA; and Charlotte Boix from the INSERM U.872 for excellent technical assistance. We also thank C. Joubert and the animal facility staff of the CEA. We acknowledge A. Aarninck and A. Blancher (University Paul Sabatier, IFR150, Toulouse, France) for MHC haplotype analysis and F. Delalande (UMR7178) for glycosylation profile analysis. We thank the EMPRO (LSHP-CT-2003503558), CHAARM (FP7-CP-IP -242135), and EuroPrise (LSHP-CT-2006037611) European programs as well as the Agence Nationale de Recherche sur le SIDA et les hépatites virales that support this program. M.E.B. was supported by a SIDACTION grant.

\section{DISCLOSURE}

The authors declared no conflict of interest.

\section{REFERENCES}

1. Florese, R.H. et al. Evaluation of passively transferred, nonneutralizing antibody-dependent cellular cytotoxicity-mediating lgG in protection of neonatal rhesus macaques against oral SIVmac251 challenge. J. Immunol. 177, 4028-4036 (2006).

2. Mascola, J.R., Frankel, S.S. \& Broliden, K. HIV-1 entry at the mucosal surface: role of antibodies in protection. AIDS 14 (Suppl 3), S167-S174 (2000).

3. Hessell, A.J. et al. Fc receptor but not complement binding is important in antibody protection against HIV. Nature 449, 101-104 (2007).

4. Hessell, A.J. et al. Broadly neutralizing human anti-HIV antibody $2 \mathrm{G} 12$ is effective in protection against mucosal SHIV challenge even at low serum neutralizing titers. PLoS Pathog. 5, e1000433 (2009).

5. Ruprecht, R.M. Passive immunization with human neutralizing monoclonal antibodies against HIV-1 in macaque models: experimental approaches. Methods Mol. Biol. 525, 559-566. xiv (2009).

6. Burton, D.R. et al. Limited or no protection by weakly or nonneutralizing antibodies against vaginal SHIV challenge of macaques compared with a strongly neutralizing antibody. Proc. Natl. Acad. Sci. USA 108, 11181-11186 (2011).

7. Gomez-Roman, V.R. et al. Vaccine-elicited antibodies mediate antibodydependent cellular cytotoxicity correlated with significantly reduced acute viremia in rhesus macaques challenged with SIVmac251. J. Immunol. 174, 2185-2189 (2005).

8. Forthal, D.N. \& Moog, C. Fc receptor-mediated antiviral antibodies, Curr. Opin. HIV AIDS 4, 388-393 (2009).

9. Rerks-Ngarm, S. et al. Vaccination with ALVAC and AIDSVAX to prevent HIV-1 infection in Thailand. N. Engl. J. Med. 361, 2209-2220 (2009).

10. Haynes, B.F. et al. Immune-correlates analysis of an HIV-1 vaccine efficacy trial. N. Engl. J. Med. 366, 1275-1286 (2012).

11. Moore, P.L. et al. Nature of nonfunctional envelope proteins on the surface of human immunodeficiency virus type 1. J. Virol. 80, 2515-2528 (2006).

12. Hessell, A.J. et al. Effective, low-titer antibody protection against low-dose repeated mucosal SHIV challenge in macaques. Nat. Med. 15, 951-954 (2009).

13. Peressin, M. et al. HIV-1 replication in Langerhans and interstitial dendritic cells is inhibited by neutralizing and Fc-mediated inhibitory antibodies. J. Virol. 85, 1077-1085 (2011).

14. Barouch, D.H. et al. Vaccine protection against acquisition of neutralization-resistant SIV challenges in rhesus monkeys. Nature 482, 89-93 (2012).

15. Baum, L.L. Role of humoral immunity in host defense against HIV. Curr. HIVIAIDS Rep. 7, 11-18 (2010).

16. Holl, V. et al. Nonneutralizing antibodies are able to inhibit human immunodeficiency virus type 1 replication in macrophages and immature dendritic cells. J. Virol. 80, 6177-6181 (2006).

17. Holl, V. et al. Involvement of Fc gamma RI (CD64) in the mechanism of HIV-1 inhibition by polyclonal IgG purified from infected patients in cultured monocyte-derived macrophages. J. Immunol. 173, 6274-6283 (2004).

18. Holl, V. et al. Efficient inhibition of HIV-1 replication in human immature monocyte-derived dendritic cells by purified anti-HIV-1 IgG without induction of maturation. Blood 107, 4466-4474 (2006).

19. Hezareh, M., Hessell, A.J., Jensen, R.C., van de Winkel, J.G. \& Parren, P.W. Effector function activities of a panel of mutants of a broadly neutralizing antibody against human immunodeficiency virus type 1 . J. Virol. 75, 12161-12168 (2001).

20. Smalls-Mantey, A. et al. Antibody-dependent cellular cytotoxicity against primary HIV-infected CD4 + T cells is directly associated with the magnitude of surface IgG binding. J. Virol. 86, 8672-8680 (2012).

21. Burrer, R., Haessig-Einius, S., Aubertin, A.M. \& Moog, C. Neutralizing as well as non-neutralizing polyclonal immunoglobulin $(\mathrm{lg}) \mathrm{G}$ from infected patients capture HIV-1 via antibodies directed against the principal immunodominant domain of gp41. Virology 333, 102-113 (2005).

22. Kent, S.J., Stent, G., Sonza, S., Hunter, S.D. \& Crowe, S.M. HIV-1 infection of monocyte-derived macrophages reduces $\mathrm{FC}_{\mathrm{C}}$ and complement receptor expression. Clin. Exp. Immunol. 95, 450-454 (1994).

23. Perez, L.G., Costa, M.R., Todd, C.A., Haynes, B.F. \& Montefiori, D.C. Utilization of immunoglobulin G Fc receptors by human immunodeficiency virus type 1: a specific role for antibodies against the membrane-proximal external region of gp41. J. Virol. 83, 7397-7410 (2009).

c 2014 Society for Mucosal Immunology 
24. Maillard, P. et al. Fcgamma receptor-like activity of hepatitis $C$ virus core protein. J Biol Chem 279, 2430-2437 (2004).

25. Siberil, S. et al. Selection of a human anti-RhD monoclonal antibody for therapeutic use: impact of IgG glycosylation on activating and inhibitory Fc gamma R functions. Clin. Immunol. 118, 170-179 (2006).

26. Chou, T.C. \& Talalay, P. Quantitative analysis of dose-effect relationships: the combined effects of multiple drugs or enzyme inhibitors. Adv. Enzyme Regul. 22, 27-55 (1984).

27. Verrier, B. et al. Evaluation in rhesus macaques of Tat and rev-targeted immunization as a preventive vaccine against mucosal challenge with SHIV-BX08. DNA Cell Biol. 21, 653-658 (2002).

28. Xu, J.Y., Gorny, M.K., Palker, T., Karwowska, S. \& Zolla-Pazner, S. Epitope mapping of two immunodominant domains of gp41, the transmembrane protein of human immunodeficiency virus type 1, using ten human monoclonal antibodies. J. Virol. 65, 4832-4838 (1991).

29. Buchacher, A. et al. Generation of human monoclonal antibodies against HIV-1 proteins; electrofusion and Epstein-Barr virus transformation for peripheral blood lymphocyte immortalization. AIDS Res. Hum. Retroviruses 10, 359-369 (1994).

30. Harouse, J.M., Gettie, A., Tan, R.C., Blanchard, J. \& Cheng-Mayer, C. Distinct pathogenic sequela in rhesus macaques infected with CCR5 or CXCR4 utilizing SHIVs. Science 284, 816-819 (1999).

31. Harouse, J.M. et al. Mucosal transmission and induction of simian AIDS by CCR5-specific simian/human immunodeficiency virus SHIV(SF162P3). J. Virol. 75, 1990-1995 (2001).

32. Warncke, M. et al. Different adaptations of IgG effector function in human and nonhuman primates and implications for therapeutic antibody treatment. J. Immunol. 188, 4405-4411 (2012).

33. Moldt, B. et al. A panel of lgG1 b12 variants with selectively diminished or enhanced affinity for Fcgamma receptors to define the role of effector functions in protection against HIV. J. Virol. 85, 10572-10581 (2011).

34. Moldt, B. et al. A nonfucosylated variant of the anti-HIV-1 monoclonal antibody b12 has enhanced FcgammaRllla-mediated antiviral activity in vitro but does not improve protection against mucosal SHIV challenge in macaques. J. Virol. 86, 6189-6196 (2012).

35. Dereuddre-Bosquet, N. et al. MiniCD4 microbicide prevents HIV infection of human mucosal explants and vaginal transmission of SHIV(162P3) in cynomolgus macaques. PLoS Pathog. 8, e1003071 (2012).

36. Moldt, B. et al. Highly potent HIV-specific antibody neutralization in vitro translates into effective protection against mucosal SHIV challenge in vivo. Proc. Natl. Acad. Sci. USA 109, 18921-18925 (2012).
37. Stoiber, H., Speth, C. \& Dierich, M.P. Role of complement in the control of HIV dynamics and pathogenesis. Vaccine 21 (Suppl 2), S77-S82 (2003).

38. Huber, M. et al. Potent human immunodeficiency virus-neutralizing and complement lysis activities of antibodies are not obligatorily linked. J. Virol. 82, 3834-3842 (2008)

39. Bialuk, I. et al. Vaccine induced antibodies to the first variable loop of human immunodeficiency virus type $1 \mathrm{gp} 120$, mediate antibody-dependent virus inhibition in macaques. Vaccine 30, 78-94 (2011).

40. Parren, P.W. et al. Antibody protects macaques against vaginal challenge with a pathogenic R5 simian/human immunodeficiency virus at serum levels giving complete neutralization in vitro. J. Virol. 75, 8340-8347 (2001).

41. Ferrantelli, F. et al. Complete protection of neonatal rhesus macaques against oral exposure to pathogenic simian-human immunodeficiency virus by human anti-HIV monoclonal antibodies. J. Infect. Dis. 189, 2167-2173 (2004).

42. Ferrantelli, F. et al. Time dependence of protective post-exposure prophylaxis with human monoclonal antibodies against pathogenic SHIV challenge in newborn macaques. Virology 358, 69-78 (2007).

43. Li, Z., Palaniyandi, S., Zeng, R., Tuo, W., Roopenian, D.C. \& Zhu, X. Transfer of IgG in the female genital tract by MHC class I-related neonatal FC receptor (FcRn) confers protective immunity to vaginal infection. Proc. Natl. Acad. Sci. USA 108, 4388-4393 (2011).

44. Kunert, R., Steinfellner, W., Purtscher, M., Assadian, A. \& Katinger, H. Stable recombinant expression of the anti HIV-1 monoclonal antibody 2F5 after lgG3/lgG1 subclass switch in $\mathrm{CHO}$ cells. Biotechnol. Bioeng. 67, 97-103 (2000).

45. Nyambi, P.N., Burda, S., Bastiani, L. \& Williams, C. A virus binding assay for studying the antigenic landscape on intact, native, primary human immunodeficiency virus-type 1. J. Immunol. Methods 253, 253-262 (2001).

46. Heyndrickx, L. et al. International network for comparison of HIV neutralization assays: the NeutNet report II. PLoS One 7, e36438 (2012).

47. Bourry, O. et al. Prevention of vaginal simian immunodeficiency virus transmission in macaques by postexposure prophylaxis with zidovudine, lamivudine and indinavir. AIDS 23, 447-454 (2009).

48. Aarnink, A. et al. Influence of the MHC genotype on the progression of experimental SIV infection in the Mauritian cynomolgus macaque. Immunogenetics 63, 267-274 (2011). 